\title{
Recombination parameters of lifetime-limiting carrier-induced defects in multicrystalline silicon for solar cells
}

Carlos Vargas, Yan Zhu, Gianluca Coletti, Catherine Chan, David Payne, Mallory Jensen, and Ziv Hameiri

Citation: Appl. Phys. Lett. 110, 092106 (2017); doi: 10.1063/1.4977906

View online: http://dx.doi.org/10.1063/1.4977906

View Table of Contents: http://aip.scitation.org/toc/apl/110/9

Published by the American Institute of Physics

\section{Articles you may be interested in}

Lifetime degradation and regeneration in multicrystalline silicon under illumination at elevated temperature AIP Advances 6, 035119 (2016); 10.1063/1.4944839

Modulating the extent of fast and slow boron-oxygen related degradation in Czochralski silicon by thermal annealing: Evidence of a single defect Journal of Applied Physics 121, 053106 (2017); 10.1063/1.4975685

Parameterisation of injection-dependent lifetime measurements in semiconductors in terms of Shockley-ReadHall statistics: An application to oxide precipitates in silicon

Journal of Applied Physics 111, 113709 (2012); 10.1063/1.4725475

Light-induced activation and deactivation of bulk defects in boron-doped float-zone silicon Journal of Applied Physics 121, 185702 (2017); 10.1063/1.4983024

Constructing submicron textures on mc-Si solar cells via copper-catalyzed chemical etching Applied Physics Letters 110, 093901 (2017); 10.1063/1.4977191

Passivation mechanism in silicon heterojunction solar cells with intrinsic hydrogenated amorphous silicon oxide layers

Journal of Applied Physics 121, 085306 (2017); 10.1063/1.4977242

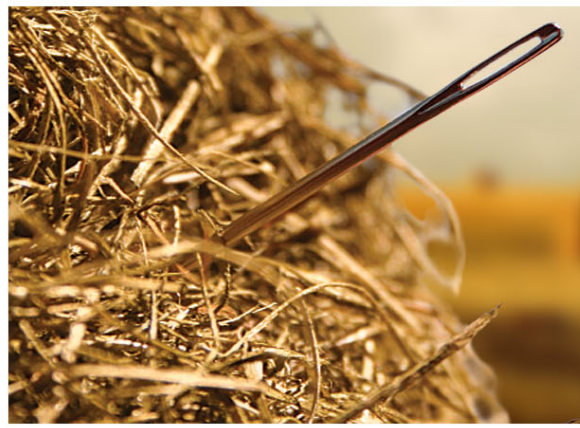

FIND THE NEEDLE IN THE HIRING HAYSTACK

POST JOBS AND REACH THOUSANDS OF QUALIFIED SCIENTISTS EACH MONTH.

PHYSICS TODAY I JOBS

WWW.PHYSICSTODAY.ORG/JOBS 


\title{
Recombination parameters of lifetime-limiting carrier-induced defects in multicrystalline silicon for solar cells
}

\author{
Carlos Vargas, ${ }^{1, \text { a) }}$ Yan Zhu, ${ }^{1, a)}$ Gianluca Coletti, ${ }^{1,2}$ Catherine Chan, ${ }^{1}$ David Payne, ${ }^{1}$ \\ Mallory Jensen, ${ }^{3}$ and Ziv Hameiri ${ }^{1}$ \\ ${ }^{1}$ The University of New South Wales, Sydney 2052, Australia \\ ${ }^{2}$ Energy Research Centre of the Netherlands (ECN Solar Energy), Petten 1755, The Netherlands \\ ${ }^{3}$ Massachusetts Institute of Technology, Cambridge, Massachusetts 02139, USA
}

(Received 5 January 2017; accepted 18 February 2017; published online 3 March 2017)

\begin{abstract}
In $p$-type multicrystalline silicon solar cells, carrier-induced degradation (CID) can cause up to $10 \%$ relative reduction in conversion efficiency. Although, a great concern has been drawn on this degradation in the photovoltaic community, the nature of this degradation is still yet unknown. In this contribution, the recombination parameters of the responsible defect causing this degradation are extracted via temperature and injection dependent lifetime spectroscopy. Three wafers from three different ingots were processed into cell precursor and lifetime structures for the study. Similar defect recombination parameters were obtained for all samples. Two candidates for the defect energy level were identified: $E_{t}-E_{i}=-(0.32 \pm 0.05) \mathrm{eV}$ or $E_{t}-E_{i}=(0.21 \pm 0.05) \mathrm{eV}$ in the lower and upper bandgap halves, respectively. The capture cross section ratios were found to be $k=56 \pm 23$ or $k=49 \pm 21$ for the lower and upper bandgap halves, respectively. Contrary to previous studies, these parameters have been extracted for the responsible defect of CID, without making assumptions regarding the defect energy level. The result allows to model and to predict the impact of this defect on the solar cell efficiency. Published by AIP Publishing.
\end{abstract}

[http://dx.doi.org/10.1063/1.4977906]

Since Ramspeck et al. ${ }^{1}$ reported a light-induced degradation of $p$-type multicrystalline silicon (mc-Si) solar cells in 2012, several studies have been carried out aiming to identify and to understand the responsible defect; ${ }^{2-5}$ however, the cause of the degradation is still unclear. Recently, a degradation of up to $10 \%$ in passivated emitter and rear contact (PERC) solar cells due to this defect has been reported. ${ }^{6}$ This is hindering the implementation of advanced cell processing in the production of photovoltaic (PV) modules. The degradation occurs under illumination and is accelerated by elevated temperature [and therefore is often referred to as light and elevated temperature-induced degradation (LeTID)] with a relatively long time constant. ${ }^{1,7}$ The degradation has been shown to be induced equivalently through current injec$\operatorname{tion}^{7,8}$ and to occur more rapidly under open-circuit compared to short-circuit conditions. ${ }^{7}$ The effect is therefore also known as the carrier-induced degradation (CID) $;^{9}$ this is the term that will be used in this study. Under similar degradation conditions, the samples eventually regenerate. However, extensive light soaking durations are typically required for substantial recovery. ${ }^{7}$

Some of the processes applied in the production of solar cells impact the CID. Particularly, the firing process used to form the metal contacts of screen printed solar cells has been shown to have a large impact on the CID extent, ${ }^{2,10-12}$ with a higher peak firing temperature leading to more severe degradation. ${ }^{10}$ It has been reported that the CID is greatly suppressed in samples that are fired at peak temperature below $600{ }^{\circ} \mathrm{C}$, or not present in non-fired samples. ${ }^{10}$ It has also recently been shown that the heating and cooling rates of the

${ }^{a)}$ C. Vargas and Y. Zhu contributed equally to this work. firing process can play a role in the extent of CID, it is even possible to avoid the CID formation using the appropriate temperature ramp-up and/or ramp-down rates. ${ }^{12}$ Moreover, it seems that phosphorus diffusion impacts the CID as less pronounced degradation was observed for wafers gettered using phosphorus in comparison to those gettered with aluminium. ${ }^{13}$

Initially, it was suggested that the defect causing CID was related to the aluminium oxide $\left(\mathrm{AlO}_{\mathrm{x}}\right)$ rear passivation layer employed to produce mc-Si PERC solar cells. ${ }^{6}$ However, recent studies have shown a similar degradation for other dielectrics used for surface passivation. ${ }^{2,9-11}$ The degradation also appears to be ubiquitous across the wafer with a strong Shockley-Read-Hall (SRH) signature in the lifetime curve. ${ }^{2,7,11,13}$ Therefore, it was concluded that the CID is most likely caused by a bulk defect. Since mc-Si wafers inherently have low interstitial oxygen concentration, and CID has also been observed in mc-Si cells doped with gallium $(\mathrm{Ga})$ instead of boron $(\mathrm{B}),{ }^{1}$ the formation of boron-oxygen complex (B-O) was excluded as the primary cause of this CID effect. Using temperatures of about $70^{\circ} \mathrm{C}$ and light intensities near $1000 \mathrm{~W} / \mathrm{m}^{2}$, the degradation time constant is very long (hundreds of hours). It requires an even longer time to recover, this fact further excludes the candidature of the B-O complex. ${ }^{14}$ Recently, Inglese et al. investigated copper $(\mathrm{Cu})$ contaminated $\mathrm{B}$-doped and $\mathrm{Ga}-$ doped mc-Si wafers and reported an enhanced CID that was attributed by them to $\mathrm{Cu}^{5}$

A few studies have aimed to identify the ShockleyRead-Hall parameters of the responsible defect using injection dependent lifetime spectroscopy (IDLS) technique. ${ }^{2-4}$ The IDLS involves a fitting of measured lifetime to the SRH 
equation. ${ }^{15,16}$ A linearization of the SRH equation proposed by Murphy et al. ${ }^{17}$ significantly simplifies the fitting process. The fitting result is usually presented as the defect parameter solution surface (DPSS) curves. ${ }^{18}$ The DPSS curves define all the possible combinations of energy levels and capture cross section ratios in the defect parameter constellation. ${ }^{19}$ However, due to its ambiguity, a single IDLS is unable to pinpoint out the exact defect parameters from a DPSS curve. Using IDLS, Nakayashiki et al. $^{2}$ determined a value of capture cross section ratio $k=\sigma_{n} / \sigma_{p}=28.5$ by assuming a midgap defect. ${ }^{2}$ Bredemeier et $a l .{ }^{4}$ reported a value of $k=20 \pm 7$ also assuming a mid-gap defect. Recently, Morishige et al. ${ }^{3}$ reported a defect energy level within the wide range $-0.27 \mathrm{eV}<E_{t}-E_{i}<0.13 \mathrm{eV}$ and an asymmetry factor in the range $26<k<36$ using a sensitivity analysis of the (DPSS) curve. All the reported values are based on single IDLS measurements performed at room temperature (RT), therefore the reported capture cross section ratios are all based on the assumption of the energy level.

One way to determine the unique solution from the DPSS curve is to measure the IDLS at various temperatures. ${ }^{18}$ This method is known as the temperature- and injection-dependent lifetime spectroscopy (TIDLS). ${ }^{18,20}$ By plotting the DPSS curves at different temperatures together, the exact defect parameters should be identified by the intersections of the DPSS curves, if $E_{t}$ and $k$ are assumed to be independent of temperature. $^{18}$

Recently, a customized TIDLS system has been developed in our laboratory. Measurements can be carried out over a wide temperature range between $-170{ }^{\circ} \mathrm{C}$ and $400^{\circ} \mathrm{C}$. The system uses both photoconductance (PC) and photoluminescence (PL) sensors to measure the effective carrier lifetime. The PL sensor extends the measurement range and significantly improves the quality of the data collected at low injection levels. $^{21,22}$ This system was used here to investigate various mc-Si wafers.

Three different $6^{\prime \prime}$ wafers from three different ingots were used in this study. Wafer A was a high performance $(\mathrm{HP})^{23} \mathrm{mc}-\mathrm{Si}$ wafer with a thickness of $180 \mu \mathrm{m}$ and resistivity of $1.8 \Omega \mathrm{cm}$ (bulk doping $N_{A}=8.1 \times 10^{15} \mathrm{~cm}^{-3}$ ), Wafer $\mathrm{B}$ was a conventional mc-Si wafer with a thickness of $244 \mu \mathrm{m}$ and resistivity of $1.5 \Omega \mathrm{cm}\left(N_{A}=9.7 \times 10^{15} \mathrm{~cm}^{-3}\right)$, and Wafer $\mathrm{C}$ was also a conventional mc-Si wafer with a thickness of $193 \mu \mathrm{m}$ and resistivity of $1.8 \Omega \mathrm{cm}\left(N_{A}=8.1\right.$ $\left.\times 10^{15} \mathrm{~cm}^{-3}\right)$. Wafer A was prepared by the provider as a PERC cell precursor (asymmetric structure): The front side was phosphorus-diffused and was passivated using silicon nitride $\left(\mathrm{SiN}_{\mathrm{x}}\right)$ deposited by plasma enhanced chemical vapour deposition (PECVD), while the rear side was passivated using an $\mathrm{AlO}_{\mathrm{x}} / \mathrm{SiN}_{\mathrm{x}}$ stack also using PECVD. Wafers $\mathrm{B}$ and $\mathrm{C}$ were prepared as symmetric lifetime structures, using RCA (Radio Corporation of America) chemical clean followed by phosphorus diffusion $(80 \Omega / \square)$ carried out in a Tempress $\mathrm{POCl}_{3}$ tube, followed by an hydrofluoric acid (HF) dip before a $\mathrm{SiN}_{\mathrm{x}}$ deposition $(75 \mathrm{~nm}$ thickness and refraction index of 2.1) from a Meyer Burger MAiA PECVD system onto both sides. This scheme provides good surface recombination with a saturation current density below $80 \mathrm{fA} / \mathrm{cm}^{2}$. Wafer A was fired as a $6^{\prime \prime}$ wafer at $785^{\circ} \mathrm{C}$ (actual measured temperature) and was then laser cleaved into small $4 \times 4 \mathrm{~cm}^{2}$ pieces. Wafers $\mathrm{B}$ and $\mathrm{C}$ were laser cleaved into small $4 \times 4 \mathrm{~cm}^{2}$ pieces and were fired with a peak temperature of $790{ }^{\circ} \mathrm{C}$ (actual measured temperature). Initial TIDLS measurements were carried out at this stage at the following temperatures: $-25^{\circ} \mathrm{C}, 0{ }^{\circ} \mathrm{C}, 25^{\circ} \mathrm{C}, 50^{\circ} \mathrm{C}$ and $75^{\circ} \mathrm{C}$. The actual sample temperature was calibrated with sister wafers with the same thickness and size, and the temperature difference in this temperature range was found to be within $1^{\circ} \mathrm{C}$, which is negligible for the DPSS analysis.

As mentioned before, under normal conditions, the degradation and regeneration process takes several hundreds of hours. Recently, Payne et al. developed a method to accelerate the formation and subsequent mitigation of the defect based on high intensity illumination (laser) and high temperatures. ${ }^{8,9}$ Therefore, we degrade our wafers using a laseraccelerated process at a temperature of $140{ }^{\circ} \mathrm{C}$ and light intensity of $46 \mathrm{~kW} \mathrm{~m}^{-2}$, similar to the process described in Ref. 9. The process was monitored every $10 \mathrm{~s}$ until a fully degraded state was achieved (see Fig. 1). Maximum degradation was obtained after $20 \mathrm{~s}$ for Wafer $\mathrm{C}$ and after $50 \mathrm{~s}$ for Wafers A and B.

After the degradation, TIDLS measurements were performed at the same temperatures used before the degradation. The maximum temperature was chosen to be below $100{ }^{\circ} \mathrm{C}$ to avoid recovery of the lifetime during the measurement itself. ${ }^{24}$ In order to identify any change during the measurement, the effective lifetime at room temperature was measured before and after the TIDLS measurements. Across the whole injection level, the change of lifetime was within $5 \%$, suggesting that the defect state does not change during the TIDLS measurement.

The SRH lifetime of the defect $\left(\tau_{C I D}\right)$ was extracted using the harmonic difference between the effective lifetime before degradation $\left(\tau_{\text {int }}\right)$ and the degraded lifetime $\left(\tau_{\text {deg }}\right)$ at each temperature as

$$
\tau_{C I D}=\left(\frac{1}{\tau_{d e g}}-\frac{1}{\tau_{\text {int }}}\right)^{-1} .
$$

Figure 2 presents the representative measurements before and after the degradation, together with the harmonic

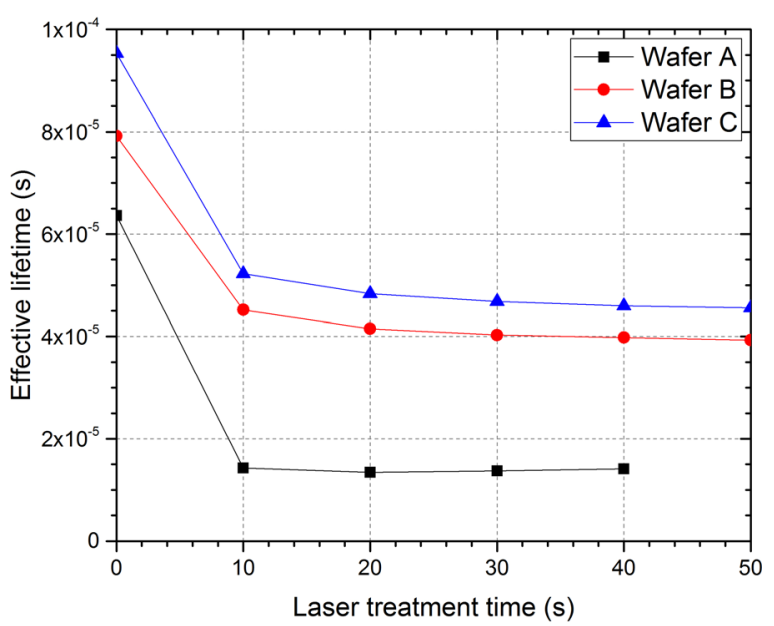

FIG. 1. Effective lifetime at an excess carrier concentration of $1 \times 10^{15} \mathrm{~cm}^{-3}$ as a function of time duration of the laser degradation process. The lines are a guide to the eye. 


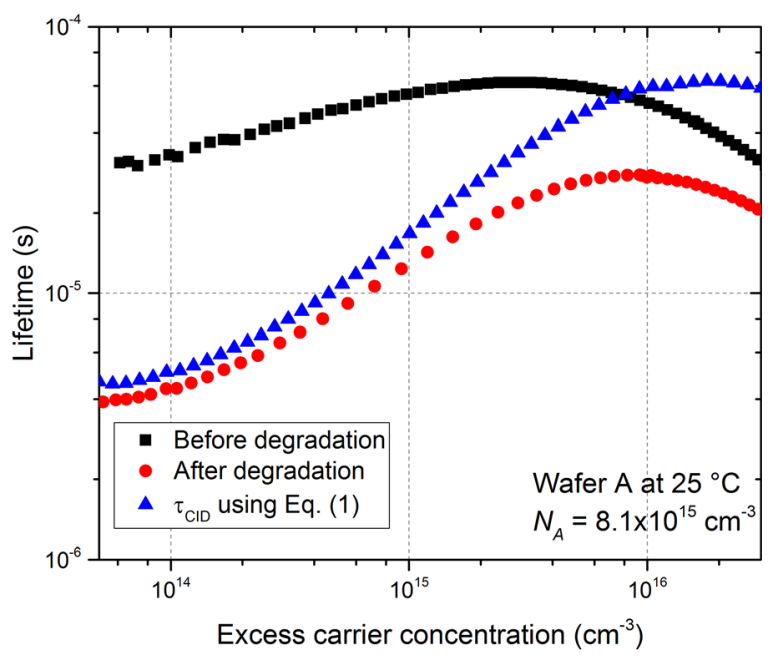

FIG. 2. Lifetimes (at $25^{\circ} \mathrm{C}$ ) of Wafer A before and after the degradation process. The CID-related defect lifetime obtained by the difference between the curves is presented as well.

differential lifetime for Wafer A at RT. Using harmonic difference has the significant advantage that recombination components that do not change during the degradation will not impact the analysis; this includes the intrinsic recombination and other crystallographic defects present in mc-Si wafers. The change in the surface saturation current density due to the degradation process was found to be insignificant and therefore its impact is also removed by the harmonic difference.

Subsequently, the $\tau_{C I D}$ data was linearized using the variable change $X=n / p$, following the method presented by Murphy et al., ${ }^{17}$ where $n$ and $p$ are the total electron and hole concentrations, respectively. In Fig. 3 , the $\tau_{C I D} v s . X$ of Wafer A at RT is shown. As can be seen, the curve is not linear, indicating the existence of more than one defect. ${ }^{3}$ As expected, least square fitting using one defect does not provide an acceptable fit; a better fit is achieved when two defects are considered (see Fig. 3). Although not satisfactory, we first considered one defect and one temperature (RT) in order to compare our results with those of Bredemeier et al. ${ }^{4}$ Assuming a mid-gap defect (as indeed assumed in Ref. 4),

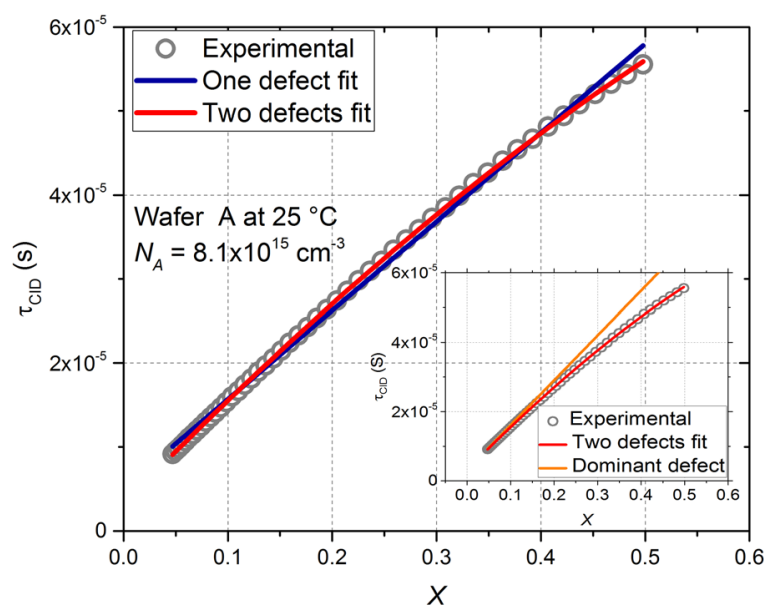

FIG. 3. $\tau_{C I D}$ linearization of Wafer A (at $25^{\circ} \mathrm{C}$ ), together with the best fit obtained by one defect and two defects. The inset presents the dominant defect. we determined an asymmetry factor of $k=17$, which is within the range of $k=20 \pm 7$ reported by Bredemeier et al. ${ }^{4}$ We then considered two defects; we have identified one defect that dominates the entire injection range (see Fig. 3); similar to Ref. 3, we also identified a shallow defect, which has only a weak impact on the lifetime (mainly at high injection). Following Ref. 3, a sensitivity analysis to account for $10 \%$ uncertainties in the measurement of lifetime, as well as excess carrier density, was performed for the dominant defect using only one temperature (RT) for comparison. An asymmetry factor in the range of $29<k<33$ was obtained assuming a mid-gap defect, which is within the range of $26<k<36$ reported by Morishige et al. ${ }^{3}$

Once good agreement with previous studies was confirmed, we extended the analysis to include all of the temperatures $\left(-25^{\circ} \mathrm{C}\right.$ to $\left.75^{\circ} \mathrm{C}\right)$. The DPSS of the asymmetry factor (DPSS- $k$ ), based on the TIDLS data is shown in Fig. 4 for Wafer A. As typical with TIDLS analysis, two regions where the DPSS- $k$ curves intersect can be easily recognised. ${ }^{18}$ If the defect is located in the bottom band-gap half, the defect parameters are: $-0.33 \mathrm{eV}<E_{t}-E_{i}<-0.28 \mathrm{eV}$ and $33<k$ $<45$. If the defect is located in the upper band-gap half, a similar capture cross section ratio is determined to be $29<k<44$, while the energy level is determined as $0.17 \mathrm{eV}<E_{t}-E_{i}<0.22 \mathrm{eV}$. The difference of the average energy depth (the energy gap between the defect's level and the intrinsic Fermi level) of these two possible solutions is $|-0.30|-|0.19|=0.11 \mathrm{eV}$. Theoretically, this difference can be calculated as $\Delta E(T)=k_{b} T \ln \left(k N_{c} / N_{v}\right)$, where $k_{b}$ is the Boltzmann constant, and $N_{c}$ and $N_{v}$ are respectively the density of states in the conduction band and valence band. ${ }^{18}$ Considering the uncertainty ranges of the obtained $k$ value, the theoretical $\Delta E$ is within the range from $0.08 \mathrm{eV}$ to $0.12 \mathrm{eV}$; a range that includes the determined difference $(0.11 \mathrm{eV})$. The intersections in the upper bandgap half appear to be slightly more spread than those at a lower bandgap half. However, the two solutions provide similar quality of fitting. Therefore, we cannot confirm the band-gap half at this stage. We also tested the method suggested in Ref. 20 to distinguish the bandgap-half, but it also failed. The fact that

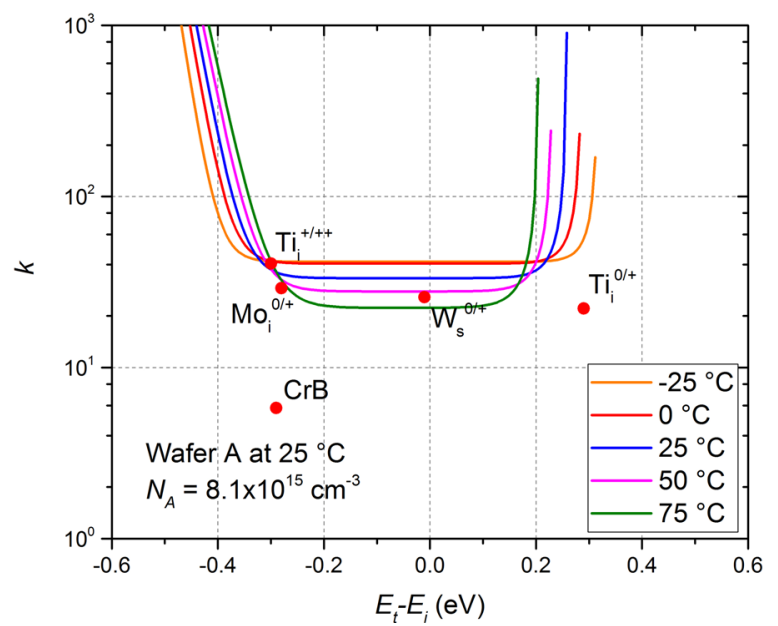

FIG. 4. DPSS- $k$ of Wafer A, together with the recombination parameters of a few metal impurities with similar $E_{t}$ and/or $k$. The $E_{t}$ and $k$ values are taken from Refs. 20 and 25-27. 
there is a relatively sharp intersection region in the lower bandgap half indicates that $k$ might have no strong temperature dependency in the measurement temperature range. However, it is also possible that the true energy level is in the upper bandgap half, and $k$ decreases with temperature.

Similar recombination parameters were obtained for Wafers B and C (see Table I). Note that the uncertainty range of defect parameters are taken from all the possible intersections of the DPSS curves without further assumptions.

As shown in Table I, the energy level values obtained from the different wafers are very similar (within the uncertainty range), despite the varying degradation extent (see Fig. 1), different structures (symmetric lifetime structure vs. PERC precursor) and different growth methods (conventional vs. HP mc-Si wafers). Combining the three wafers, we estimate the defect energy level to be $E_{t}-E_{i}=-(0.32 \pm 0.05)$ $\mathrm{eV}$ for the defect in the bottom band-gap half or $E_{t}-E_{i}$ $=(0.21 \pm 0.05) \mathrm{eV}$ for the defect in the upper bandgap half. The asymmetry factor was determined to be $k=56 \pm 23$ or $k=49 \pm 21$ for the bottom or upper bandgap halves respectively. The value of $k$ is higher than the one reported by Bredemeier $e t a l .{ }^{4}$ and by Morishige et al. ${ }^{3}$ The difference is solely explained by the assumption in the position of the energy level. As shown above, if a mid-gap defect is assumed, the obtained $k$ values are similar to those of previous studies. By TIDLS, the energy level and capture cross section ratio are pinpointed out from the defect parameter constellation without any assumption.

In Fig. 4, known parameters of a few metallic impurities are also presented. ${ }^{3,26}$ The $E_{t}$ and $k$ of the CID-related defect found here are similar to those of an interstitial titanium double donor $\left(\mathrm{Ti}_{\mathrm{i}}^{+1++}, E_{t}-E_{i}=-0.30 \mathrm{eV}\right.$ and $k=40.4$ (Ref. 20)) and an interstitial molybdenum donor $\left(\mathrm{Mo}_{\mathrm{i}}{ }^{\mathrm{O}+}, E_{t}\right.$ $-E_{i}=-0.28 \mathrm{eV}$ and $k=25.4$ (Ref. 26)). Morishige et al. ${ }^{3}$ also considered an interstitial tungsten donor $\left(\mathrm{W}_{\mathrm{i}}^{0 /+}, E_{t}-E_{i}\right.$ $=-0.01 \mathrm{eV}$ and $k=25.8$ (Ref. 27)) as one of the possible candidates of the root-cause for the CID; however, this possibility could be discarded based on this study, as the energy levels do not correspond. It is important to note the large uncertainties are associated with $k$ values in literature of many impurities. At this stage, we must also consider the option that the defect responsible has not yet been characterized and identified by deep-level transient spectroscopy (DLTS) or any other method.

In conclusion, three mc-Si wafers from three different ingots were processed into cell precursors and lifetime structures, and CID defects were generated. The defect recombination parameters were investigated using TIDLS. The

TABLE I. Recombination parameters obtained for the different wafers.

\begin{tabular}{lccc}
\hline \hline Band-gap half & Wafer & $E_{t}-E_{i}(\mathrm{eV})$ & $K$ \\
\hline Bottom & A & $-0.30 \pm 0.03$ & $39 \pm 6$ \\
& B & $-0.31 \pm 0.04$ & $59 \pm 20$ \\
Upper & C & $-0.32 \pm 0.04$ & $58 \pm 17$ \\
& A & $0.19 \pm 0.03$ & $37 \pm 8$ \\
& B & $0.20 \pm 0.05$ & $53 \pm 16$ \\
& C & $0.20 \pm 0.04$ & $55 \pm 15$ \\
\hline \hline
\end{tabular}

obtained $E_{t}$ and $k$ of the three wafers were found to be very similar, indicating an identical defect as a source of the reported CID. The energy level of the defect was determined to be $E_{t}-E_{i}=-(0.32 \pm 0.05) \mathrm{eV}$ for the bottom bandgap half or $E_{t}-E_{i}=(0.22 \pm 0.05) \mathrm{eV}$ for the top bandgap half of the defect, while the asymmetry factor $k$ was found to be $k=56 \pm 23$ for the bottom bandgap half or $k=49 \pm 21$ for the top bandgap half. This $k$ value is higher than the values previously reported; however, this result does not relay on any assumptions regarding $E_{t}$. At this stage, the defect type has not been identified; $\mathrm{Ti}_{\mathrm{i}}{ }^{+/++}$and $\mathrm{Mo}_{\mathrm{i}}{ }^{\mathrm{O}++}$ appear to have similar recombination parameters to the CID-related defect; however, we cannot rule out the possibility of an as-yet unknown defect.

The authors acknowledge the support from the Australian Government through the Australian Renewable Energy Agency (ARENA, Project No. 2014/RND097) and through ECN (Energy research Centre of the Netherlands). The views expressed herein are not necessarily the views of the Australian Government, and the Australian Government does not accept responsibility for any information or advice contained herein. Z. Hameiri acknowledges the support of the Australian Research Council (ARC) through the Discovery Early Career Researcher Award (DECRA, Project No. DE150100268), while M. Jensen acknowledges the support of the National Science Foundation (NSF) Graduate Research Fellowship under Grant No. 1122374 and NSF Graduate Research Opportunities Worldwide.

${ }^{1}$ K. Ramspeck, S. Zimmermann, H. Nagel, A. Metz, Y. Gassenbauer, B. Birkmann, and A. Seidl, in 27th European Photovoltaic Solar Energy Conference (2012), p. 861.

${ }^{2}$ K. Nakayashiki, J. Hofstetter, A. E. Morishige, T. T. A. Li, D. B. Needleman, M. A. Jensen, and T. Buonassisi, IEEE J. Photovoltaics 6, 860 (2016).

${ }^{3}$ A. E. Morishige, M. A. Jensen, D. B. Needleman, K. Nakayashiki, J. Hofstetter, T. T. A. Li, and T. Buonassisi, IEEE J. Photovoltaics 6, 1466 (2016).

${ }^{4}$ D. Bredemeier, D. Walter, S. Herlufsen, and J. Schmidt, Energy Procedia 92, 773 (2016).

${ }^{5}$ A. Inglese, A. Focareta, F. Schindler, J. Schön, J. Lindroos, M. C. Schubert, and H. Savin, Energy Procedia 92, 808 (2016).

${ }^{6}$ F. Fertig, K. Krauß, and S. Rein, Phys. Status Solidi RRL 9, 41 (2015).

${ }^{7}$ F. Kersten, P. Engelhart, H.-C. Ploigt, A. Stekolnikov, T. Lindner, F. Stenzel, M. Bartzsch, A. Szpeth, K. Petter, J. Heitmann, and J. W. Müller, Sol. Energy Mater. Sol. Cells 142, 83 (2015).

${ }^{8}$ D. N. R. Payne, C. E. Chan, B. J. Hallam, B. Hoex, M. D. Abbott, S. R. Wenham, and D. M. Bagnall, Sol. Energy Mater. Sol. Cells 158, 102 (2016).

${ }^{9}$ D. N. R. Payne, C. E. Chan, B. J. Hallam, B. Hoex, M. D. Abbott, S. R. Wenham, and D. M. Bagnall, Phys. Status Solidi RRL 10, 237 (2016).

${ }^{10}$ C. E. Chan, D. N. R. Payne, B. J. Hallam, M. D. Abbott, T. H. Fung, A. M. Wenham, B. S. Tjahjono, and S. R. Wenham, IEEE J. Photovoltaics 6, 1473 (2016).

${ }^{11}$ D. Bredemeier, D. Walter, S. Herlufsen, and J. Schmidt, AIP Adv. 6, 35119 (2016).

${ }^{12}$ R. Eberle, W. Kwapil, F. Schindler, M. C. Schubert, and S. W. Glunz, Phys. Status Solidi RRL 10, 861 (2016).

${ }^{13}$ A. Zuschlag, D. Skorka, and G. Hahn, "Degradation and regeneration in mc-Si after different gettering steps," Prog. Photovoltaics (published online, 2016).

${ }^{14}$ J. Schmidt and A. Cuevas, J. Appl. Phys. 86, 3175 (1999).

${ }^{15}$ W. Shockley and W. T. Read, Phys. Rev. 87, 835 (1952).

${ }^{16}$ R. N. Hall, Phys. Rev. 87, 387 (1952).

${ }^{17}$ J. D. Murphy, K. Bothe, R. Krain, V. V. Voronkov, and R. J. Falster, J. Appl. Phys. 111, 113709 (2012). 
${ }^{18}$ S. Rein, Lifetime Spectroscopy: a Method of Defect Characterization in Silicon for Photovoltaics Applications (Springer-Verlag, Germany, 2005).

${ }^{19}$ S. Rein and S. W. Glunz, Appl. Phys. Lett. 82, 1054 (2003).

${ }^{20}$ B. B. Paudyal, K. R. McIntosh, and D. H. Macdonald, J. Appl. Phys. 105, 124510 (2009).

${ }^{21}$ T. Trupke and R. A. Bardos, in 31st IEEE Photovoltaics Specialists Conference (2005), pp. 903-906.

${ }^{22}$ Z. Hameiri, T. Trupke, N. Gao, R. A. Sinton, and J. W. Weber, Prog. Photovoltaics 21, 942 (2013).
${ }^{23}$ Y. M. Yang, A. Yu, B. Hsu, W. C. Hsu, A. Yang, and C. W. Lan, Prog. Photovoltaics 23, 340 (2015).

${ }^{24}$ T. Luka, S. Großer, C. Hagendorf, K. Ramspeck, and M. Turek, Sol. Energy Mater. Sol. Cells 158, 43 (2016).

${ }^{25}$ C. Sun, F. E. Rougieux, and D. Macdonald, J. Appl. Phys. 115, 214907 (2014).

${ }^{26} \mathrm{~K}$. Graff, Metal Impurities on Silicon Device Fabrication (SpringerVerlag, Germany, 1995).

${ }^{27}$ S. Boughaba and D. Mathiot, J. Appl. Phys. 69, 278 (1991). 